\title{
Slopes of Avian Species-Area Relationships, Human Population Density, and Environmental Factors
}

\section{Pentes des relations espèces aviaires-superficie, densité humaine et facteurs environnementaux}

\author{
$\underline{\text { Karl L. Evans }}^{1}, \underline{\text { Jack J. Lennon }}^{2}$, and Kevin J. Gaston ${ }^{1}$
}

\begin{abstract}
There is increasing interest in how humans influence spatial patterns in biodiversity. One of the most frequently noted and marked of these patterns is the increase in species richness with area, the species-area relationship (SAR). SARs are used for a number of conservation purposes, including predicting extinction rates, setting conservation targets, and identifying biodiversity hotspots. Such applications can be improved by a detailed understanding of the factors promoting spatial variation in the slope of SARs, which is currently the subject of a vigorous debate. Moreover, very few studies have considered the anthropogenic influences on the slopes of SARs; this is particularly surprising given that in much of the world areas with high human population density are typically those with a high number of species, which generates conservation conflicts. Here we determine correlates of spatial variation in the slopes of speciesarea relationships, using the British avifauna as a case study. Whilst we focus on human population density, a widely used index of human activities, we also take into account (1) the rate of increase in habitat heterogeneity with increasing area, which is frequently proposed to drive SARs, (2) environmental energy availability, which may influence SARs by affecting species occupancy patterns, and (3) species richness. We consider environmental variables measured at both local $(10 \mathrm{~km} \times 10 \mathrm{~km})$ and regional $(290 \mathrm{~km} \times 290$ $\mathrm{km}$ ) spatial grains, but find that the former consistently provides a better fit to the data. In our case study, the effect of species richness on the slope SARs appears to be scale dependent, being negative at local scales but positive at regional scales. In univariate tests, the slope of the SAR correlates negatively with human population density and environmental energy availability, and positively with the rate of increase in habitat heterogeneity. We conducted two sets of multiple regression analyses, with and without species richness as a predictor. When species richness is included it exerts a dominant effect, but when it is excluded temperature has the dominant effect on the slope of the SAR, and the effects of other predictors are marginal.
\end{abstract}

RÉSUMÉ. Il existe un intérêt croissant à propos de l'influence que l'humain exerce sur les patrons spatiaux de la biodiversité. Un des patrons les plus importants et les plus fréquemment notés est l'augmentation de la richesse spécifique avec la superficie de l'habitat, soit la relation espèce-superficie (species-area relationship; SAR). Les SAR sont utilisées à diverses fins de conservation, telles la prédiction du taux d'extinction, la définition d'objectifs de conservation et l'identification de points chauds de biodiversité. De telles applications peuvent être améliorées grâce à une compréhension approfondie des facteurs qui agissent sur la variation spatiale de la pente des SAR, facteurs qui font actuellement l'objet d'un débat vigoureux. De plus, très peu d'études ont tenu compte de l'influence anthropique sur la pente des SAR. Ceci est particulièrement surprenant sachant qu'en général, dans le monde, les endroits qui ont une forte densité humaine sont typiquement ceux qui hébergent un grand nombre d'espèces, ce qui conflictuel en termes de conservation. Dans cette étude, nous établissons les corrélats de la variation spatiale des pentes des SAR, en utilisant le cas de l'avifaune britannique. Bien que nous nous concentrions sur la densité

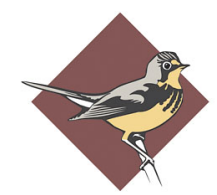

BIRD STUDIES CANADA 
humaine, un indice de l'activité humaine très largement utilisé, nous prenons aussi en compte : 1) le taux d'augmentation de l'hétérogénéité de l'habitat avec l'accroissement de la superficie, fréquemment invoqué en tant que cause des SAR; 2) la disponibilité d'énergie dans l'environnement, qui peut influencer les SAR en affectant les patrons d'occupation des espèces; 3 ) la richesse spécifique. Nous avons examiné les variables environnementales à l'échelle spatiale locale $(10 \mathrm{~km} \times 10 \mathrm{~km})$ et régionale $(290 \mathrm{~km} \times 290 \mathrm{~km})$, mais avons observé que l'échelle locale s'ajustait systématiquement mieux aux données. Dans notre étude, l'effet de la richesse spécifique sur la pente des SAR semble dépendre de l'échelle, puisqu'il est négatif à des échelles locales, mais positif à des échelles régionales. Les tests univariés révèlent que la pente de la SAR est corrélée négativement à la densité humaine et à la disponibilité d'énergie dans l'environnement; elle est corrélée positivement au taux d'augmentation de l'hétérogénéité de l'habitat. Nous avons réalisé deux séries d'analyses de régression multiple, avec et sans la richesse spécifique comme variable explicative. Lorsque la richesse spécifique est incluse dans l'analyse, elle exerce un effet dominant, mais lorsqu'elle est exclue, c'est la température qui exerce l'effet dominant sur la pente de la SAR; les autres variables explicatives ont un effet marginal.

Key Words: habitat diversity; human population density; macroecology; spatial statistics; species-area relationships.

\section{INTRODUCTION}

An emerging research agenda in conservation biology is exploring the impact of humans on largescale, i.e., macroecological, spatial patterns in biodiversity (Gaston 2004). Such studies typically use human population density as an index of human activity and have largely focused on the spatial congruence of species richness and human population density. The two are typically positively correlated, which generates conservation conflicts (Balmford et al. 2001, Luck et al. 2004, Gaston 2005, Evans et al. 2006, 2007). Rather little research has, however, been conducted that investigates the influence of humans on other spatial patterns in biodiversity (Gaston and Blackburn 2003, Gaston 2004, 2005, 2006). One of the earliest, most frequently noted and most marked of these patterns is the increase in species richness with area, i.e., the species-area relationship or SAR (Arrhenius 1921). Studies of human influence on SARs are particularly limited, being confined to preliminary investigations into the effects of human induced variation in habitat heterogeneity (Ma et al. 2002), and the influence of species introductions (Pyšek 1998, Moody 2000).

This lack of attention to human influences on SARs contrasts with the intense theoretical debate surrounding their mathematical form and underlying causal factors (e.g., Connor and McCoy 1979, Sugihara 1981, Wissel and Maier 1992, Holt
1993, Leitner and Rosenzweig 1997, Storch et al. 2003, Tjørve 2003, Turner and Tjørve 2005). There is also much empirical evidence that spatial patterns in habitat diversity contribute to SARs, although it can be difficult to define habitats in a manner that is independent of their species composition, particularly with regard to botanical diversity (Rosenzweig 1995). A steep increase in habitat diversity with area generally promotes steeper SARs (Williams 1964, Ricklefs and Lovette 1999, Storch et al. 2003, Triantis et al. 2003). However, spatial variation in the slope of the SAR and its ecological correlates have been explored much less frequently and intensively than other spatial patterns in biodiversity, such as species richness (but see Diniz-Filho et al. 2004, Rodríguez and Arita 2004, Drakare et al. 2006).

Despite uncertainty in the factors generating SARs, and variation in their slope, they have been used for a number of conservation purposes. These include, but are by no means limited to, the following. First, SARs are used to predict extinction rates following habitat loss as a consequence of factors such as deforestation or climate change (Cowlishaw 1999, Kinzig and Harte 2000, Brashares et al. 2001, Brooks et al. 2002, Seabloom et al. 2002, Brook et al. 2003, Thomas et al. 2004, Malcolm et al. 2006). Second, and closely related to the first, is the use of SARs to predict extinction rates in isolated blocks of fragmented habitat, including protected areas (Báldi and Vörös 2006, Benedick et al. 2006, 
Watling and Donelley 2006). Third, SARs are used to predict extinction rates following reductions in habitat diversity (Thrush et al. 2006). Fourth, they are used to assess the conservation value of alternative management options (Santos et al. 2006). Fifth, SARs are employed to estimate the amount of habitat that must be protected to maintain a target number of species in a biome (Desmet and Cowling 2004). Finally, SARs are used to assist in the identification of biodiversity hotspots by facilitating comparison between surveys that cover different spatial extents, or in identifying hotspots as sites that contain more species than expected given their area (Veech 2000, Hobohm 2003, van Gemerden et al. 2005, Werner and Buszko 2005, Fattorini 2006).

In these conservation applications one of the key parameters of interest is the slope of the SAR. For example, following a given rate of habitat loss, a greater proportion of species will be lost in regions with steep SARs than those with shallow ones. Also, in regions with shallower SARs a greater proportion of regional richness will be found in a given area of protected land than in regions with steeper SARs. Furthermore, the identity of the mechanisms generating the SAR is of fundamental importance to some of these applied uses. An obvious example is that using the SAR to make predictions regarding the impacts of loss of habitat diversity on species richness assumes that spatial patterns in habitat diversity play a key role in generating the SAR (Thrush et al. 2006). Clearly, if the factors and mechanisms influencing the slope of the SAR could be identified then resulting conservation recommendations could be made more accurate (Lewis 2006).

Methodological concerns may have hindered explorations of spatial variation in SARs and their correlates, including human population density. In continental landscapes, SARs are typically constructed by laying a nested series of quadrats of increasing size over species distribution maps, thus generating data on species richness in a number of different sized areas. In such analyses the largest quadrats typically overlap (e.g. Diniz-Filho et al. 2004, Rodríguez and Arita 2004) and thus the resultant SARs are not entirely independent of each other. This non-independence can be removed by arranging the largest quadrats in a non-overlapping manner, but doing so typically results in an insufficient number of SARs being available to describe spatial variation in their slope, and for formal statistical analysis. Reducing the size of the largest quadrat seldom yields a sufficient number of additional SARs to enable statistical analysis, and reduces the number of data-points that are available to construct the individual SARs, which reduces their robustness and explanatory power.

Analytical techniques are now available that take the effects of spatial non-independence, i.e., spatial autocorrelation, within data into account. This enables one to investigate the environmental correlates of spatial variation in the slope of SARs constructed using overlapping quadrats, whilst remaining free of concerns regarding the nonindependence of the SARs (Lennon et al. 2001). Analyses that take spatial non-independence into account are variously described as mixed-effects modeling, spatial regression analysis or geostatistical analysis, and are increasingly employed in macroecology studies. They estimate the nature of spatial non-independence and adjust parameter estimates and significance tests accordingly. Crucially, this adjustment occurs regardless of the causes of the spatial non-independence; therefore, even if measurement procedures generate spatial autocorrelation, application of spatial statistical analyses can correctly take account of the nonindependence and allow formal hypothesis testing (Cressie 1993, Legendre 1993, Littell et al. 1996, Lennon 2000, Lennon et al. 2001, Legendre et al. 2002, Haining 2003, Fortin and Dale 2005).

Here we use published data on spatial variation in the SARs of British breeding birds as a case study to explore the environmental and anthropogenic correlates of such variation. These data were collated using an overlapping nested quadrat design and we use analyses that take spatial autocorrelation into account in order to remove the problems associated with non-independence. Our primary interest is to investigate how the slope of SARs responds to spatial variation in human population density. In general, high human population density is associated with a homogenization of biotas (Lockwood et al. 2000, McKinney 2005) and this may reduce the slope of SARs in densely populated regions. We also test the frequently stated hypothesis that a steep increase in habitat diversity with area will result in steeper SARs (Preston 1960, Cam et al. 2002), and investigate the relationship between human population density and the rate of change in habitat diversity with increasing area. Our analyses also take into account environmental energy availability as this exerts a strong influence on spatial patterns in species richness (Hawkins et 
al. 2003, Evans et al. 2005a). Moreover, environmental energy availability may exert additional influences on the form of the SAR by influencing occupancy patterns (Storch et al. 2005). If species occupy only a few localities then SARs are steeper than if species were widely distributed such that, for example, if every species occupied all areas then the SAR would be flat (Leitner and Rosenzweig 1997, Šizling and Storch 2004).

Finally, we also investigate how taking species richness into account influences our conclusions. The primary reason for doing so is that species richness may influence the slope of the SAR by affecting how many species from the regional species pool remain to be added to an area. Such effects depend, however, on spatial patterns in occupancy. For example, a region of low species richness may contain a small number of species that occupy most of the area and thus have a shallow SAR, or contain an equal number of localized species and thus have a steep SAR. There is thus no a priori reason why species richness should influence the form of the SAR; indeed other studies of the relationship between species richness and the slope of the SAR have found no relationship between these variables (Diniz-Filho et al. 2004). In addition, species richness is positively correlated with temperature and human population density, and thus including species richness as a predictor also makes the test of the effects of temperature and human population density more conservative.

\section{METHODS}

\section{Avian species-area data}

We used data on spatial variation in the form of the SAR in British breeding birds obtained from Lennon et al. (2001); this reference provides a full explanation of how these data were calculated and a summary is given here.

Data originate from the summer breeding distribution of the British avifauna recorded in April-July 1988-1991, shown in the second BTO/ SOC/IW atlas of breeding birds (Gibbons et al. 1993). They record species presence/absence at a resolution of $10 \mathrm{~km} \mathrm{x} 10 \mathrm{~km}$ quadrats on a continuous grid. Fieldwork was coordinated by a network of regional organizers and undertaken by experienced volunteer ornithologists. Data are based on timed visits, of two hours duration, to at least eight $2 \mathrm{~km} \times 2 \mathrm{~km}$ quadrats within each $10 \mathrm{~km}$ quadrat and supplemented with additional records collated over the four survey years. There is little evidence for geographical bias in sampling efficiency and for most quadrats very few species are likely to have gone unrecorded (Gibbons et al. 1993, Evans et al. 2007); we thus consider our data to be free of significant concerns regarding undersampling (see Cam et al. 2002). These constitute one of the best sets of distributional data for any assemblage and have been successfully used in numerous macroecological studies (e.g., Gaston and Blackburn 2000, 2002, Lennon et al. 2000, 2001). Following Lennon et al. (2001) we excluded 21 marine species and vagrants, i.e., those that do not regularly breed in Britain and are recorded as a few individuals typically in only one or two quadrats, but retained the more naturalized introductions and some species that bred sporadically, giving a total of 196 species. Some initial filtering was performed on the distributional data; $10 \mathrm{~km}$ quadrats that contained less than $50 \%$ land were excluded, leaving a total of 2406 quadrats.

For each of these focal $10 \mathrm{~km}$ quadrats species richness and area data were gathered by expanding the size of a "window" whose center was the original $10 \mathrm{~km}$ quadrat. The size of the window used increased from $10 \mathrm{~km} \times 10 \mathrm{~km}$ to $290 \mathrm{~km} \times 290 \mathrm{~km}$, in steps of $20 \mathrm{~km}$, giving 15 data points. The SAR for a focal quadrat was based on a nested series of larger quadrats, i.e., increasing scales, centered on this focal square. As spatial grain increased, these larger squares typically contained larger areas of sea, but only land area was used in the estimation of the SAR. We created a separate SAR for each 10 $\mathrm{km}$ quadrat using two alternative SAR models. These were the $\log$ (species)-log(area) relationship $\log \mathrm{S}=c+z \log \mathrm{A}($ the power SAR, Arrhennius 1921) and the species- $\log ($ area) relationship $\mathrm{S}=k+m \log \mathrm{A}$ (the semi-logarithmic SAR, Gleason 1922). In these equations $\mathrm{S}$ and $\mathrm{A}$ respectively represent species richness and area, whilst $z$ and $m$ measure the slopes of SARs and $c$ and $k$ are constants. These SARs provided a very good fit to the data with mean $r^{2}$ values of $96 \%$ and $98 \%$, respectively for the power and semi-logarithmic SAR.

\section{Habitat diversity}

Habitat data were obtained using the land use classification of Fuller et al. (1994), which is based on extensively ground-truthed remote sensing data 
that were collected in 1990 thus coinciding with the timing of the avian survey. We used two habitat classification schemes. The first, fine scale classification retained 24 of the original 25 land cover types, and sea was omitted; the second, broad scale classification amalgamated some of these into seven main habitat types: coastal, inland water, moor/heathland/bog, woodland, grassland, tilled land, built environment (Table 1). These broad habitat types include the six main types that influence avian distributions in Britain and all of the main habitats used in a previous analysis of how habitat heterogeneity influences avian species richness in Britain (Gibbons et al. 1993, Lennon et al. 2000).

For each of our two habitat classification schemes we calculated two measures of habitat heterogeneity (1) the number, i.e., richness, of habitat types, and (2) habitat diversity, calculated using the ShannonWiener information index (Ludwig and Reynolds 1988). This index combines data on both the presence and size of each habitat type and was used because species may respond to the extent of each habitat type, not just its presence. For each focal 10 km quadrat we calculated how habitat heterogeneity increased with area by subtracting the measure of habitat heterogeneity at the largest spatial grain (290 $\mathrm{km}$ quadrat) from that in the focal quadrat.

\section{Environmental energy availability}

The productivity of an environment limits the amount of energy available to consumers, which in turn can influence spatial patterns in species richness through a number of mechanisms (Evans et al. 2005b). In high northern latitudes such as Britain plant productivity is not markedly influenced by water availability, and thus temperature can be used as a surrogate measure of plant productivity (Hawkins et al. 2003). In addition, the thermoregulatory load hypothesis suggests that high temperatures may reduce the energetic requirements of endotherms by enabling them to divert resources away from maintaining their body temperature (Lennon et al. 2000). An alternative surrogate measure of plant productivity is the Normalized Difference Vegetation Index (NDVI), which is a satellite derived measure of the greenness of vegetation and empirical data demonstrate that NDVI is strongly and positively correlated with plant productivity (Boelman et al. 2003, Kerr and Ostrovosky 2003).
In this paper we use both temperature and NDVI as measures of environmental energy availability. We obtained mean monthly temperature data that were derived from meteorological recording station readings for the period 1961-90 using surface interpolation techniques (Barrow et al. 1993). Second, we obtained NDVI data from the NOAA/ NASA Pathfinder AVHRR Land Data Set. These data were collected between 1981 and 2001 at a spatial resolution of a $0.1^{\circ}$ latitude/longitude grid. Daily readings are converted to maximum values for each $10 \mathrm{~d}$ period, which markedly reduces the effects of cloud cover (see http://www.ciesin.org/ ) .

From these we calculated mean monthly NDVI values and then used GIS to reproject these data at a $10 \mathrm{~km}$ resolution, which was compatible with our avian distribution data. For both temperature and NDVI we calculated a mean annual measure of energy availability and a mean summer value from the monthly averages for May, June, and July. Although these variables have a rather limited range compared to those that occur globally, they exhibit marked spatial variation and are significant predictors of spatial variation in avian species richness in Britain (Lennon et al. 2000, Evans and Gaston 2005, Evans et al. 2005a).

\section{Human population density}

Human density data were obtained by allocating 1991 census data to each quadrat. The data used were $200 \mathrm{~m} \times 200 \mathrm{~m}$ squares to which population had been attributed by means of a smoothed redistribution, using a distance-decay-weighted function at enumeration district centroids (Martin and Tate 1997). These data were then summed to give the number of people in each $10 \mathrm{~km}$ quadrat and converted to densities $\left(\mathrm{km}^{-2}\right)$. To reduce the skew in the distribution of human density values we used $\log _{10}$ values in our analyses. Prior to logarithmic transformation one was added to all values to enable the transformation of zeros.

\section{Analyses}

Using the moving window approach to calculate SARs the larger quadrats overlap, creating nonindependence in the data. In the context of describing spatial variation in the form of SARs and analyzing the correlates of this variation this 
Table 1. Broadscale and fine-scale habitat classification schemes based on Fuller et al. (1994). The finescale habitat classification scheme also included three habitat types, i.e., bracken, ruderal weed, inland bare ground, which were not amalgamated into broadscale habitat types.

\begin{tabular}{ll}
\hline \hline Broadscale habitat type & Fine-scale habitat type \\
\hline Inland water & Inland water \\
Coastal & Beach and coastal bare, salt marsh \\
Moor/heathland/bog & Grass heath, moorland grass, open shrub moor, dense shrub moor, dense shrub \\
hoodland open shrub heath, lowland bog, upland bog
\end{tabular}

approach is the only one available, as the alternative of using nonoverlapping quadrats yields insufficient data points for formal statistical analysis. For example, if the size of the largest quadrat used was $200 \mathrm{~km}$ fewer than ten SARs could be constructed across Britain. We apply spatial analyses that take spatial autocorrelation into account and remove concerns regarding the non-independence generated by overlapping quadrats.

All of our analyses took spatial autocorrelation into account using the PROC MIXED procedure in SAS version 8.2 (Littell et al. 1996). These models implement spatial correlation models that fit a spatial covariance matrix to the data and use this to adjust parameter estimates and test statistics accordingly (Littell et al. 1996). Exponential spatial covariance models gave a better fit to the data, assessed by Akaike information criteria (AIC), than alternative covariance structures, i.e., spherical, Gaussian, linear, linear log, and power, and were thus used in all analyses. Unsurprisingly, spatial exponential null models provided a much better fit to the data than an independent error null model for both logarithmic and power SARs judged both by AIC, and likelihood ratio tests: $\chi^{2}>2683.9$, $P<0.0001)$.
Our analyses consisted of three steps. First, as an initial exploratory analysis we conducted univariate regressions of the slope of the SARs against species richness and each of our four predictor variables, $i$. e., rate of increase in habitat heterogeneity from the $10 \mathrm{~km}$ to the $290 \mathrm{~km}$ quadrat, human population density, temperature, and NDVI. Each of these variables, except the rate of increase in habitat heterogeneity, could arguably be measured over any of the 15 quadrat sizes covered by the SARs and we thus used these environmental variables measured at both the finest $(10 \mathrm{~km})$ and largest $(290 \mathrm{~km})$ quadrat sizes. The aim of these initial analyses was to ascertain which form of each variable, e.g., which of our four measures of habitat heterogeneity, provided the best fit to the data and this variable was used subsequently in multiple regression analyses. We used an information theoretic approach to assess the fit of competing variables, selecting that with the smallest Akaike Information Criteria (AIC) value as providing the most parsimonious fit to the data (Burnham and Anderson 2001, Ginzburg and Jensen 2004, Johnson and Omland 2004).

Second, we investigated the relationship between human population density and the rate of increase in habitat heterogeneity. Our aim was to assess the potential for humans to modify the slope of the SAR 
indirectly by influencing spatial patterns in habitat heterogeneity. We regressed the rate of increase in the broad-scale Shannon-Weiner habitat diversity index against human density, using linear, square, and cubic terms of the latter. Separate analyses were conducted using data on human population density at the $10 \mathrm{~km}$ and $290 \mathrm{~km}$ scales. We constructed a full set of models that contained all possible combinations of our predictors and then used AIC values to compare the fit of competing models. Following Johnson and Omland (2004) we calculated the weight of each model, i.e., the probability that it provides the most parsimonious fit to the data.

Third, we constructed multiple regression models of the slope of the SAR using the rate of increase in habitat diversity, species richness, temperature, NDVI, and human population density as predictors. For each of these predictors we used the form that our exploratory univariate analyses indicated provided the best fit to data on the slope of SARs (Table 2). We constructed all possible models given our set of predictor variables and again used an information theoretic approach to model selection (Johnson and Omland 2004).

\section{RESULTS}

Exploratory analyses indicated that human population density, temperature, NDVI and species richness consistently explained more of the spatial variation in the slope of the SAR when measured at the $10 \mathrm{~km} \times 10 \mathrm{~km}$ spatial grain than at the $290 \mathrm{~km}$ $\times 290 \mathrm{~km}$ spatial grain. They also indicated that more of the variation in the slope of the SAR was explained by (1) summer rather than annual temperature; (2) annual rather than summer NDVI; and (3) the broadscale Shannon-Weiner habitat diversity index rather than any of the three other habitat heterogeneity measures (Table 2). These variables were thus selected for use in subsequent analyses. The influence of species richness on the slope of SARs appears to be scale dependent; correlations were negative at local scales $(10 \mathrm{~km} \times$ $10 \mathrm{~km}$ grain, Fig. 1a) but positive at large scales $(290 \mathrm{~km} \times 290 \mathrm{~km}$ grain, Fig. 1b). For both the power and semi-logarithmic SARs the switch in the sign of the relationship occurs at spatial grains between $50 \mathrm{~km}$ and $70 \mathrm{~km}$. The slopes of the SARs were positively correlated with the rate of increase in habitat diversity (Fig. 1c), and negatively correlated with energy availability (Fig. 1e, 1f) and human population density (Fig. 1g).

Relationships between human population density and the rate of increase in habitat diversity were not simple, but were consistently weak regardless of the spatial scale at which human population density was measured (Fig. 2; Table 3).

For both the power and semi-logarithmic SARs the best fitting models had a high model weight, i.e., probability of providing the most parsimonious fit to the data, and retained species richness, temperature, and NDVI as predictors, all of which correlated negatively with the slopes of SARs; with the effect of species richness dominating that of other variables (Table 4a). The second best fitting models of both the power and semi-logarithmic SARs also retained the rate of increase in habitat heterogeneity as a significant predictor, but the latter was not consistently positively correlated with the slopes of the SARs. Moreover, the support for these models was very limited, as indicated by their low model weights (Table 4a). When species richness was excluded as a predictor, the best model retained temperature, NDVI, and the rate of increase in habitat heterogeneity; with the effect of temperature being dominant (Table 4b). Log-transformed human density was only retained in the second best fitting model of spatial variation in the slope of the logarithmic SAR, and its explanatory power was very negligible (Table $4 b$ ).

\section{DISCUSSION}

For breeding birds across Britain, there was spatial variation in whether the power or semi-logarithmic SAR provided the best description of the pattern of species occurrence. The latter outperformed the power SAR in $76 \%$ of quadrats, and gave a significantly better fit in areas of low species richness at the $10 \mathrm{~km}$ scale (Lennon et al. 2001). Despite this, analyses based on power and semilogarithmic SARs yield qualitatively identical results and conclusions, suggesting that it may be possible to compare directly the results of studies that differ in the mathematical methods used to construct SARs.

Our results suggest that the relationship between species richness and the slope of the SAR can exhibit 
Table 2. Relationships in univariate spatial models between the slope of the power and semi-logarithmic species-area relationships (SARs), and measures of the rate of increase in habitat heterogeneity (from 10 $\mathrm{km}$ to $290 \mathrm{~km}$ quadrats); temperature; normalized difference vegetation index (NDVI, a measure of plant productivity); human population density, and species richness. Model fit is measured by Akaike Information Criteria (AIC), and we report $\triangle \mathrm{AIC}$ values, i.e., the difference between the focal model's AIC and that of the best fitting model, i.e., that with the smallest AIC. These exploratory analyses were conducted to decide which form of each variable should be included in subsequent multiple regression analyses. The selected variables, based on AIC values, were: increase in broad habitat diversity, summer temperature $(10 \mathrm{~km}$ grain), annual NDVI (10 km grain), $\log _{10}$ human density (10 km grain), and species richness (10 km grain). Parameter estimates for the intercept and predictor variables are provided, with positive and negative effects indicated by + and - respectively. Note that $r^{2}$ values cannot be calculated from these spatial models, but are reported for nonspatial equivalents solely to give an indication of explanatory power.

\begin{tabular}{|c|c|c|c|c|c|c|c|c|c|}
\hline \multirow[b]{2}{*}{ Predictor } & \multirow[b]{2}{*}{$\begin{array}{l}\text { Spatial g- } \\
\text { rain }(\mathrm{km})\end{array}$} & \multicolumn{4}{|c|}{ Slope of power SAR $(z)$} & \multicolumn{4}{|c|}{ Slope of semi-log SAR $(m)$} \\
\hline & & Intercept & Predictor & $\Delta \mathrm{AIC}$ & $r^{2}$ & Intercept & Predictor & $\Delta \mathrm{AIC}$ & $r^{2}$ \\
\hline Increase in fine habitat richness & $10-290$ & 0.110 & +0.002 & 219.3 & 0.39 & 13.558 & +0.165 & 278.4 & 0.36 \\
\hline Increase in broad habitat richness & $"$ & 0.119 & +0.007 & 207.1 & 0.25 & 14.141 & +0.538 & 258.0 & 0.25 \\
\hline Increase in fine habitat diversity & $"$ & 0.109 & +0.032 & 0.4 & 0.11 & 13.346 & +2.333 & 10.1 & 0.16 \\
\hline Increase in broad habitat diversity & $"$ & 0.113 & +0.043 & 0.0 & 0.08 & 13.668 & +3.100 & 0.0 & 0.11 \\
\hline Summer temperature & 10 & 0.356 & -0.017 & 0.0 & 0.25 & 31.292 & -1.223 & 0.0 & 0.29 \\
\hline$"$ & 290 & 0.292 & -0.012 & 221 & 0.20 & 28.058 & -1.000 & 241.5 & 0.25 \\
\hline Annual temperature & 10 & 0.269 & -0.017 & 20.2 & 0.16 & 24.921 & -1.226 & 8.5 & 0.22 \\
\hline$"$ & 290 & 0.201 & -0.011 & 36.5 & 0.13 & 22.131 & -1.005 & 250.1 & 0.15 \\
\hline Summer NDVI & 10 & 0.162 & -0.067 & 20.7 & 0.12 & 16.0 & -2.695 & 2.9 & 0.08 \\
\hline$"$ & 290 & 0.437 & -0.509 & 13.8 & 0.20 & 32.983 & -30.08 & 10.6 & 0.17 \\
\hline Annual NDVI & 10 & 0.166 & -0.086 & 0.0 & 0.70 & 16.619 & -4.449 & 0.0 & 0.05 \\
\hline " & 290 & 0.276 & -0.295 & 24.1 & 0.80 & 23.672 & -17.802 & 8.4 & 0.08 \\
\hline $\log _{10}$ human density & 10 & 0.137 & -0.009 & 0.0 & 0.22 & 15.448 & -0.628 & 0.0 & 0.25 \\
\hline " & 290 & 0.217 & -0.043 & 23.3 & 0.32 & 20.617 & -2.850 & 74.1 & 0.31 \\
\hline Species richness & 10 & 0.257 & -0.002 & 0.0 & 0.88 & 24.187 & -0.112 & 0.0 & 0.86 \\
\hline " & 290 & -2.116 & +0.013 & 3225.5 & 0.32 & 138.64 & +0.856 & 5826.2 & 0.43 \\
\hline
\end{tabular}


Fig. 1. Changes in the slope, $\mathrm{m}$, of the semi-logarithmic species-area relationship in British breeding birds along environmental gradients: species richness measured in (a) $10 \mathrm{~km}$ and (b) $290 \mathrm{~km}$ quadrats, (c) the rate at which broadscale habitat diversity increases from a $10 \mathrm{~km}$ to a $290 \mathrm{~km}$ quadrat, (d) temperature (10 km quadrat), (e) annual NDVI (10 km quadrat), and (f) human population density (10 km quadrat).

a)

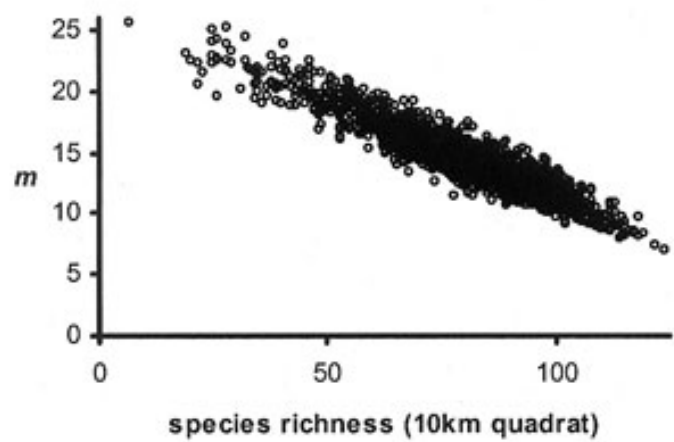

c)

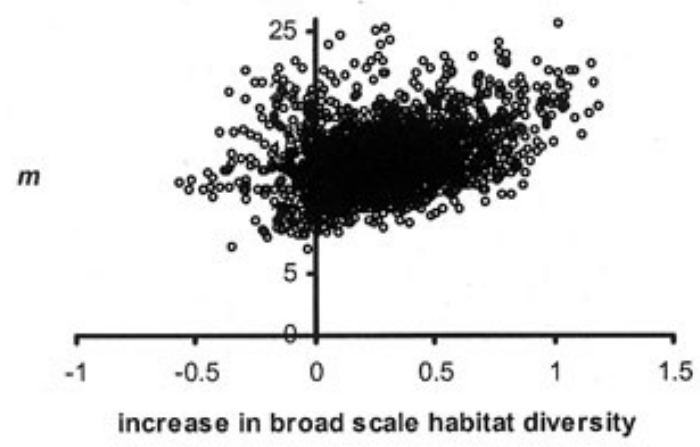

e)

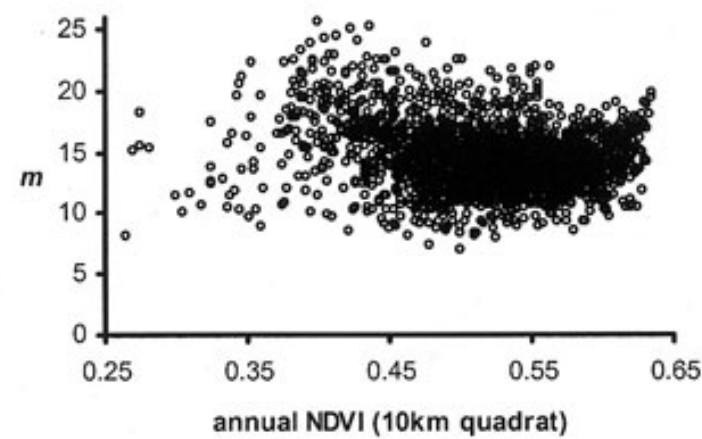

b)

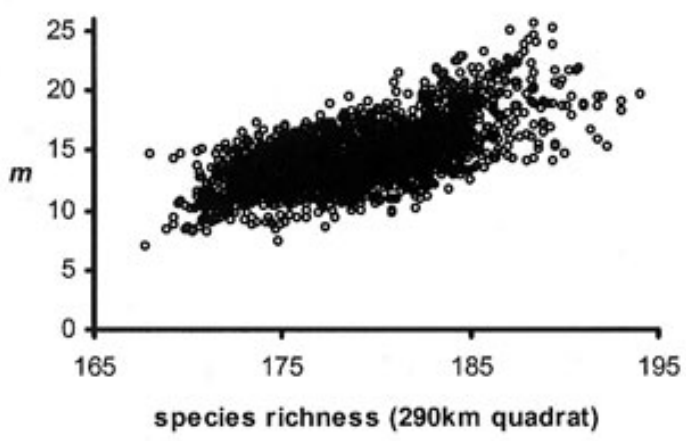

d)

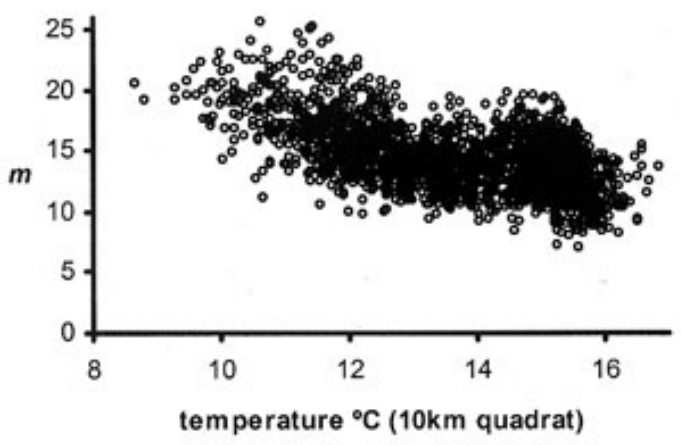

f)

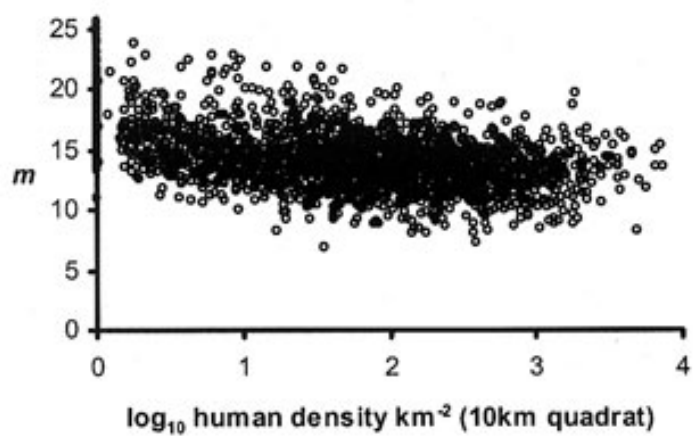


Fig. 2. The relationship between human population density and the rate at which broadscale habitat diversity increases with area.

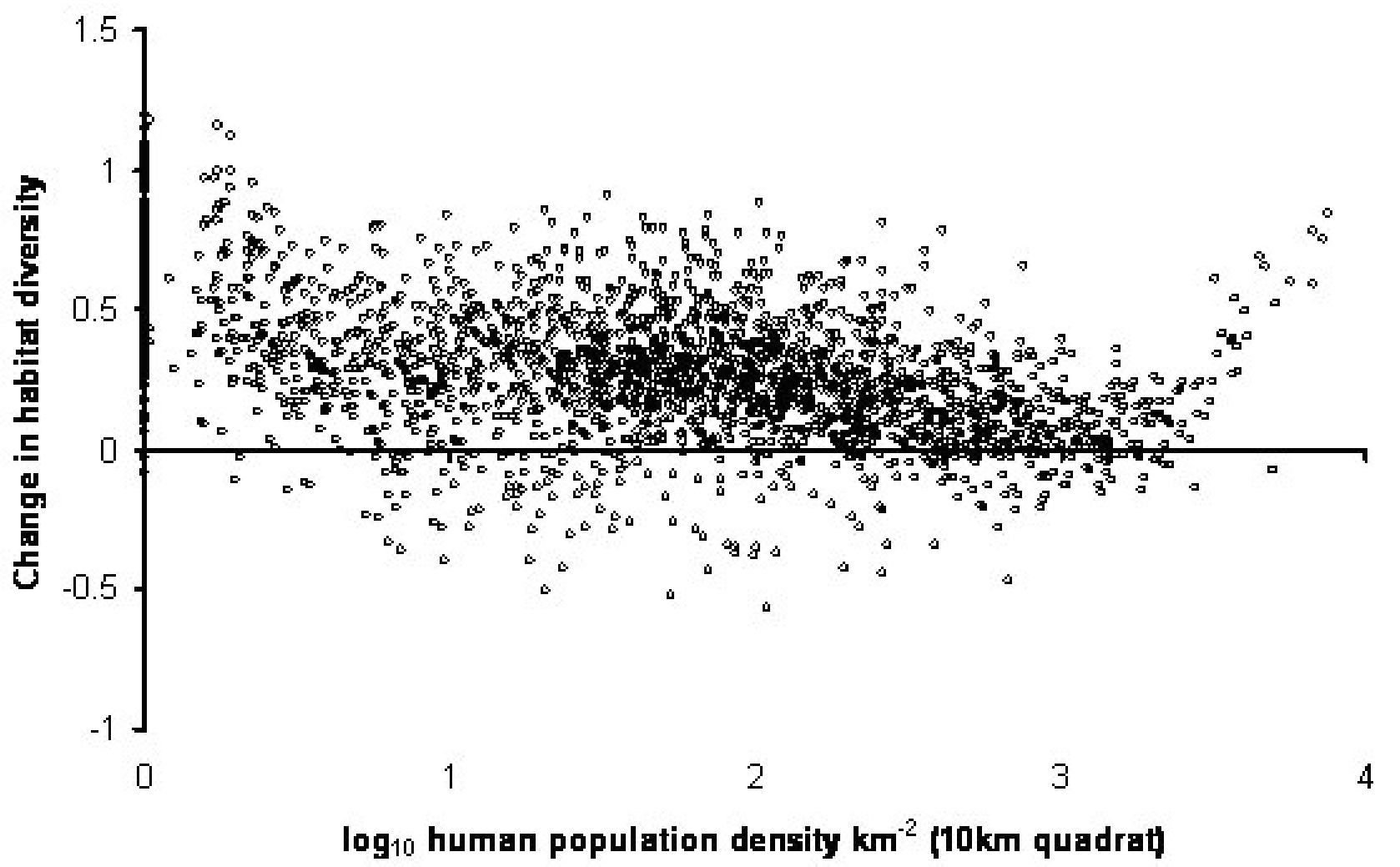

scale dependence. High levels of regional species richness will, all other things being equal, increase the probability of encountering novel species when focal quadrats are expanded to larger areas, thus increasing the slopes of SARs. Negative correlations between the species richness of the focal quadrat and the slope of the SAR probably arise because high focal richness means that fewer novel species in the regional species pool remain to be added to an area. In our case study local richness exerts a stronger effect on the slope of the SAR than regional richness. This situation probably arises because there is rather little variation in the number of species occurring in the largest quadrats relative to variation in focal cell richness, thus the upper end of the SAR curve is relatively fixed compared to the lower end. Our results contrast with an investigation of South American owl diversity in which species richness did not influence the slope of the power SAR (Diniz-Filho et al. 2004).

At least in Britain, human density has a negligible impact on spatial patterns in the accumulation of habitat heterogeneity as area increases. It thus appears unlikely that humans indirectly affect the slope of SARs through their impact on spatial patterns in habitat diversity, at least at the spatial scales that we analyze. This conclusion does not mean that humans do not influence the distributions of different habitat types, or habitat diversity at spatial scales finer than $10 \mathrm{~km}$ quadrats (Benton et al. 2003). Rather it indicates that at the spatial scale of our analysis any effects of humans on habitat diversity are either small or spatially inconsistent, 
Table 3. Relationships in spatial mixed models between the rate at which habitat diversity, measured with a broad habitat classification, increases with area from $10 \mathrm{~km}$ to $290 \mathrm{~km}$ quadrats and $\log _{10}$ transformed human population density using linear, square, and cubic terms of the latter. Two sets of analyses were conducted using predictors measured at either the $10 \mathrm{~km}$ or the $290 \mathrm{~km}$ spatial grain. Model fit is measured by Akaike Information Criteria (AIC), and here we report $\triangle \mathrm{AIC}$ values, i.e., the difference between the focal model's AIC and that of the best fitting model, i.e., that with the smallest AIC. Model weights are provided in brackets and represent the probability that the model provides the most parsimonious fit to the data out of those created. Following Johnson and Omland (2004) we present the best set of competing models, i.e., that with a cumulative model weight of 0.9. Parameter estimates for the intercept and predictor variables are provided, with positive and negative effects indicated by + and - respectively. Note that $r^{2}$ values cannot be calculated from these spatial models, but are reported for nonspatial equivalents solely to give an indication of explanatory power.

\begin{tabular}{lccccc}
\hline \hline Spatial grain & Intercept & $\begin{array}{c}\log _{10} \text { human } \\
\text { density }\end{array}$ & $\log _{10}$ human density & $\begin{array}{c}\Delta \text { AIC } \\
\text { (model weight) }\end{array}$ & model $r^{2}$ \\
\hline $10 \mathrm{~km}$ & 0.574 & -0.282 & +0.040 & $0.0(0.900)$ & 0.02 \\
$290 \mathrm{~km}$ & 0.162 & +0.044 & & $0.0(0.544)$ & 0.01 \\
$"$ & -0.405 & +0.728 & -0.185 & $1.1(0.314)$ & 0.01 \\
& & & & \\
\hline
\end{tabular}

and thus do not systematically influence the manner in which habitat heterogeneity changes with spatial grain.

The rate of increase in habitat diversity is positively correlated with the slopes of SARs in univariate tests, but not when taking the dominant effect of species richness into account. These results occur despite our use of an established habitat classification system that has previously been shown to influence the distributions of British birds (Gibbons et al. 1993, Lennon et al. 2000), and our exploration of the effects of using a variety of alternative measures of habitat heterogeneity. Few studies have assessed how the rate of increase in habitat heterogeneity, rather than habitat diversity per se, influences the slopes of SARs although the former is more relevant (Cam et al. 2002). The one study to test this found that the slopes of SARs for North American avian assemblages were unrelated to the rate at which habitat diversity increases with area (Cam et al. 2002). Such patterns may arise because whilst increasing habitat diversity increases the extent of some habitat types it concomitantly decreases the extent of other habitat types. Species may thus vary in their response to increasing habitat diversity depending on whether their preferred habitat type increases or decreases. These positive and negative effects on the distributions of individual species may cancel each other out to yield little net gain in species richness as habitat diversity increases. If such patterns are general they clearly have important implications for the use of SARs in predicting the effects of loss of habitat diversity on species richness (e.g., Thrush et al. 2006).

The best fitting multiple regression models retained a negative effect on the slopes of SARs of temperature and NDVI that were apparent in univariate regressions. The explanatory power of these measures of environmental energy was very limited in multiple regression models that retained species richness as a predictor (maximum partial $\left.\mathrm{r}^{2}=0.03\right)$, but not those that excluded species richness (maximum partial $r^{2}=0.18$ ). The change is presumably a consequence of the strong positive relationship between species richness and environmental energy, and the dominant effect of the former on spatial variation in the slope of the SAR (Evans et al. 2005a). The effect of energy 
Table 4. Multiple regression spatial mixed models of the slopes of SARs (a) with, and (b) without species richness as a predictor. All predictor variables, except the rate of increase in habitat heterogeneity, are measured at the $10 \mathrm{~km}$ scale. Model fit is measured by Akaike Information Criteria (AIC), and here we report $\triangle \mathrm{AIC}$ values, i.e. the difference between the focal model's AIC and that of the best fitting model (that with the smallest AIC). Model weights are provided in brackets and represent the probability that the model provides the best fit to the data out of those created. We provide each best fitting model until a cumulative model weight of 0.9 is achieved and this set of models represents the best candidate set of models (Johnson and Omland 2004). Parameter estimates for the intercept and predictor variables are provided. Note that $r^{2}$ values cannot be calculated from these spatial models, but are reported for nonspatial equivalents solely to give an indication of explanatory power. We provide both the model $\mathrm{r}^{2}$ value and partial $\mathrm{r}^{2}$ values for each predictor, the latter being in square brackets.

(a)

\begin{tabular}{lccccccc}
\hline \hline \multicolumn{1}{c}{ response } & intercept & $\begin{array}{l}\text { species } \\
\text { richness }\end{array}$ & summer temp & annual NDVI & $\begin{array}{c}\text { rate of } \\
\text { increase in } \\
\text { habitat diversity }\end{array}$ & $\begin{array}{c}\Delta \text { AIC } \\
\text { (model weight) }\end{array}$ & $\begin{array}{c}\text { model } \\
\mathbf{r}^{2}\end{array}$ \\
\hline$z$-from power SAR & 0.299 & $-0.002[0.62]$ & $-0.002[0.01]$ & $-0.032[0.03]$ & & $0.0(0.89)$ & 0.893 \\
$"$ & 0.306 & $-0.002[0.62]$ & $-0.003[0.02]$ & $-0.007[0.03]$ & $-0.003[0.010]$ & $5.0(0.08)$ & 0.899 \\
& 25.402 & $-0.111[0.58]$ & $-0.076[0.03]$ & $-0.891[0.002]$ & & $0.0(0.70)$ & 0.889 \\
$\begin{array}{l}\text { SAR - from semi-log } \\
\text { " }\end{array}$ & 25.273 & $-0.111[0.57]$ & $-0.068[0.03]$ & $-0.878[0.004]$ & $+0.057[0.002]$ & $2.5(0.20)$ & 0.891
\end{tabular}

(b)

\begin{tabular}{|c|c|c|c|c|c|c|c|}
\hline response & intercept & summer temp & annual NDVI & $\begin{array}{c}\text { rate of } \\
\text { increase in } \\
\text { habitat diversity }\end{array}$ & $\underset{\text { density }}{\log _{10} \text { human }}$ & $\begin{array}{c}\Delta \text { AIC } \\
\text { (model weight) }\end{array}$ & $\underset{\mathbf{r}^{2}}{\operatorname{model}}$ \\
\hline$z$ - from power SAR & 0.308 & $-0.012[0.152]$ & $-0.054[0.025]$ & $+0.032[0.011]$ & & $0.0(0.91)$ & 0.284 \\
\hline $\begin{array}{l}m \text { - from semi-log } \\
\text { SAR }\end{array}$ & 26.347 & $-0.832[0.183]$ & $-2.118[0.013]$ & $+2.413[0.018]$ & & $0.0(0.76)$ & 0.325 \\
\hline " & 26.541 & $-0.856[0.048]$ & $-2.051[0.014]$ & $+2.465[0.010]$ & $-0.057[0.007]$ & $2.8(0.19)$ & 0.332 \\
\hline
\end{tabular}

availability on the slope of SARs that is not a direct consequence of the species-energy relationship may arise through the influence of environmental energy on occupancy patterns as high occupancy results in a shallower SAR (Leitner and Rosenzweig 1997, Šizling and Storch 2004). Indeed in the British avifauna high levels of environmental energy availability increases mean species occupancy, i.e., the average number of localities that each species occupies (Evans et al., unpublished manuscript). Our results complement those of Storch et al. (2005) who found that environmental energy availability had a negative influence on the slope of SARs for avian assemblages in both Britain and South Africa, but who did not take other factors into account. 
Human density is negatively correlated with the slopes of SARs in univariate tests, but this effect is not apparent in multiple regression models. The latter relationship probably arises because across most of Britain human population density correlates positively with species richness because both of these variables respond in a similar manner to temperature (Evans and Gaston 2005a, Evans et al. 2007), and the negative influence of species richness and temperature on the slope of the SAR dominates the effects of all other predictors. There is thus little evidence that the current distribution of the human population has a major direct influence on spatial variation in the slope of avian SARs. Historical data on avian distributions in Britain suggest that a relatively small proportion of British breeding bird species, such as the Corncrake Crex crex, have experienced sizeable range contractions as a consequence of human activities and a similarly small number have expanded their ranges, such as the Siskin Carduelis spinus (Holloway 1996). These historical data are mapped at the resolution of counties, and are thus of insufficient quality formally to investigate temporal changes in the slope of SARs, although it appears unlikely that the latter changes have been large. The lack of evidence that humans have a marked influence on spatial variation in the slope of the SAR in Britain may arise because most of the region has been modified by humans over a period of many thousands of years. Humans may have a greater impact on the slope of the SAR in regions with more marked spatial variation in the magnitude of human influence on species distributions.

Responses to this article can be read online at: http://www.ace-eco.org/vol2/iss2/art7/responses/

\section{Acknowledgments:}

We thank the thousands of volunteers who gathered the atlas data and the British Trust for Ornithology for making them available. J.A. Diniz-Filho, J.J.D. Greenwood, O. Petchey, and two anonymous referees provided useful comments and discussion. K.L.E was supported by The Leverhulme Trust and the Natural Environment Research Council; K.J.G. holds a Royal Society-Wolfson Research Merit Award.

\section{LITERATURE CITED}

Arrhennius, O. 1921. Species and area. Journal of Ecology 9:95-99.

Báldi, A., and J. Vörös. 2006. Extinction debt of Hungarian reserves: a historical perspective. Basic and Applied Ecology 7:289-295.

Balmford, A., J. L. Moore, T. Brooks, N. Burgess, L. A. Hansen, P. Williams, and C. Rahbek. 2001. Conservation conflicts across Africa. Science 291:2616-2619.

Barrow, E., M. Hulme, and T. Jiang. 1993. A 1961-90 baseline climatology and future climatic change scenarios for Great Britain and Europe. Part 1, 1961-90 Great Britain baseline climatology. University of East Anglia Climatic Research Unit, Norwich, UK.

Benedick, S., J. K. Hill, N. Mustaffa, V. K. Chey, M. Maryati, J. B. Searle, M. Schilthuizen, and K. C. Hamer. 2006. Impacts of rain forest fragmentation on butterflies in northern Borneo: species richness, turnover and the value of small fragments. Journal of Applied Ecology 43:967-977.

Benton, T. G., J. A. Vickery, and J. D. Wilson. 2003. Farmland biodiversity: is habitat heterogeneity the key? Trends in Ecology and Evolution 18: $182-188$.

Boelman, N. T., M. Stieglitz, H. M. Rueth, M. Sommerkorn, K. L. Griffin, G. R. Shaver, and J. A. Gamon. 2003. Response of NDVI, biomass, and ecosystem gas exchange to long-term warming and fertilization in wet sedge tundra. Oecologia 135:414-421.

Brashares, J. S., P. Arcese, and M. K. Sam. 2001. Human demography and reserve size predict wildlife extinction in West Africa. Proceedings of the Royal Society, London B 268:2473-2478.

Brook, B. W., N. S. Sodhi, and P. K. L. Ng. 2003. Catastrophic extinctions follow deforestation in Singapore. Nature 424:420-423.

Brooks, T. M., R. A. Mittermeier, C. G. Mittermeier, G. A. B. da Fonseca, A. B., Rylands, W. R. Konstant, P. Flick, J. Pilgrim, S. Oldfield, G. Magin, and C. Hilton-Taylor. 2002. Habitat loss and extinction in the hotspots of biodiversity. Conservation Biology 16:909-923. 
Burnham, K. P., and D. R. Anderson. 2001. Kullback-Leibler information as a basis for strong inference in ecological studies. Wildlife Research 28:111-119.

Cam, E., J. D. Nichols, J. E. Hines, J. R. Sauer, R. Alpizar-Jara, and C. H. Flather. 2002. Disentangling sampling and ecological explanations underlying species-area relationships. Ecology 83:118-1130.

Connor, E. F., and E. D. McCoy. 1979. The statistics and biology of the species-area relationship. American Naturalist 113:791-833.

Cowlishaw, G. 1999. Predicting the pattern of decline of African primate diversity: an extinction debt from historical deforestation. Conservation Biology 13:1183-1193.

Cressie, N. 1993. Statistics for spatial data. Wiley, New York, New York, USA.

Desmet, P., and R. Cowling. 2004. Using the species-area relationship to set baseline targets for conservation. Ecology and Society 9(2):11. http://w ww.ecologyandsociety.org/vol9/iss2/art11/.

Diniz-Filho, J. A. F., T. F. L. V. B. Rangel, and B. A. Hawkins. 2004. A test of multiple hypotheses for the species richness gradient of South American owls. Oecologia 140:633-638.

Drakare, S., Lennon, J. J., and H. Hillebrand. 2006. The imprint of the geographical, evolutionary and ecological context on species-area relationships. Ecology Letters 9:215-227.

Evans, K. L., and K. J. Gaston. 2005. People, energy and avian species richness. Global Ecology and Biogeography 14:187-196.

Evans, K. L., J. J. D. Greenwood, and K. J. Gaston. 2005a. Dissecting the species-energy relationship. Proceedings of the Royal Society, London B 272:2155-2163.

Evans, K. L., P. H. Warren, and K. J. Gaston. 2005b. Species-energy relationships at the macroecological scale: a review of the mechanisms. Biological Reviews 80:1-25.

Evans, K. L., B. J. van Rensburg, K. J. Gaston, and S. L. Chown. 2006. People, species richness and human population growth. Global Ecology and Biogeography 15:625-636.

Evans, K. L., J. J. D. Greenwood, and K. J. Gaston. 2007. The positive correlation between avian species richness and human population density in Britain is not attributable to sampling bias. Global Ecology and Biogeography 16:300-304.

Fattorini, S. 2006. Detecting biodiversity hotspots by species-area relationships: a case study of Mediterranean beetles. Conservation Biology 20:1169-1180.

Fortin, M.-J. and M. Dale. 2005. Spatial analysis: a guide for ecologists. Cambridge University Press, Cambridge.

Fuller, R. M., G. B. Groom, and A. R. Jones. 1994. The land-cover map of Great Britain. An automated classification of Landsat Thematic Mapper data. Photogrammetric Engineering and Remote Sensing 60:553-562.

Gaston, K. J. 2004. Macroecology and people. Basic and Applied Ecology 4:303-307.

Gaston, K. J. 2005. Biodiversity and extinction: species and people. Progress in Physical Geography 29:239-247.

Gaston, K. J. 2006 Biodiversity and extinction: macroecological patterns and people. Progress in Physical Geography 30:258-269.

Gaston, K. J., and T. M. Blackburn. 2000. Pattern and process in macroecology. Blackwell Science, Oxford, UK.

Gaston, K. J., and T. M. Blackburn. 2002. Colonisation, extinction and the range sizes of breeding birds in Britain. Journal of Animal Ecology 71:390-399.

Gaston, K. J., and T. M. Blackburn. 2003. Macroecology and conservation biology. Pages 345-367 in T. M. Blackburn and K. J. Gaston, editors. Macroecology: concepts and consequences Blackwell Science, Oxford, UK.

Gibbons, D. W., J. B. Reid, and R. A. Chapman. 1993. The new atlas of breeding birds in Britain and Ireland, 1988-1991. T. and A. D. Poyser, London, UK. 
Ginzburg, L. R., and C. X. J. Jensen. 2004. Rules of thumb for judging ecological theories. Trends in Ecology and Evolution 19:121-126.

Gleason, H. A. 1922. On the relation between species and area. Ecology 3:158-162.

Haining, R. 2003. Spatial data analysis: theory and practice. Cambridge University Press, Cambridge, UK.

Hawkins, B. A., R. Field, H. V. Cornell, D. J. Currie, J-F. Guégan, D. M. Kaufman, J. T. Kerr, G. G. Mittelbach, T. Oberdorff, E. M. O'Brien, E. E. Porter, and J. R. G. Turner. 2003. Energy, water and broad-scale geographic patterns of species richness. Ecology 84:3105-3117.

Hobohm, C. 2003. Characterization and ranking of biodiversity hotspots: centres of species richness and endemism. Biodiversity and Conservation 12:279-287.

Holloway, S. 1996. The historical atlas of breeding birds in Britain and Ireland, 1875-1900. T. and A. D. Poyser, London, UK.

Holt, R. D. 1993. Ecology at the meso-scale: the influence of regional processes on local communities. Pages 77-88 in R. E. Ricklefs and D. Schluter, editors. Species diversity in ecological communities, historical and geographical perspectives. University of Chicago, Chicago, Illinois, USA.

Johnson, J. B., and K. S. Omland. 2004. Model selection in ecology and evolution. Trends in Ecology and Evolution 18:101-108.

Kerr, J. T., and M. Ostrovsky. 2003. From space to species, ecological applications for remote sensing. Trends in Ecology and Evolution 18:299-305.

Kinzig, A. P., and J. Harte. 2000. Implications of endemics-area relationships for estimates of species extinctions. Ecology 81:3305-3311.

Legendre, P. 1993. Spatial autocorrelation, trouble or new paradigm? Ecology 74:1659-1673.

Legendre, P., M. R. T. Dale, M. J. Fortin, J. Gurevitch, M. Hohn, and D. Myers. 2002. The consequences of spatial structure for design and analysis of ecological field surveys. Ecography $\mathbf{2 5}$ :601-615.

Leitner, W. A., and M. L. Rosenzweig. 1997. Nested species-area curves and stochastic sampling: a new theory. Oikos 79:503-512.

Lennon, J. J. 2000. Red-shifts and red herrings in geographical ecology. Ecography 23:101-113.

Lennon, J. J., J. J. D. Greenwood, and J. R. G. Turner. 2000. Bird diversity and environmental gradients in Britain: a test of the species-energy hypothesis. Journal of Animal Ecology 69:581-598.

Lennon, J. J., P. Koleff, J. J. D. Greenwood, and K. J. Gaston. 2001. The geographical structure of British bird distributions: diversity, spatial turnover and scale. Journal of Animal Ecology 70:966-979.

Lewis, O. T. 2006. Climate change, species-area curves and the extinction crisis. Philosophical Transactions of the Royal Society of London B. 361:163-171.

Littell, R. C., G. A. Milliken, W. W. Stroup, and R. D. Wolfinger. 1996. SAS ${ }^{\circledR}$ System for mixed models. SAS Institute Inc., Cary, North Carolina.

Lockwood, J., T. M. Brooks, and M. L. McKinney. 2000. Taxonomic homogenization of the global avifauna. Animal Conservation 3:27-35.

Luck, G. W., T. H. Ricketts, G. C. Daily, and M. Imhoff. 2004. Alleviating spatial conflict between people and biodiversity. Proceedings of the National Academy of Science, USA 101:182-186.

Ludwig, J. A., and J. F. Reynolds. 1988. Statistical Ecology. John Wiley and Sons, New York, New York, USA.

Ma, M., T. Sanna, and J. Helenius. 2002. Revisiting the species-area relationship in a seminatural habitat: floral richness in agricultural buffer zones in Finland. Agriculture, Ecosystems and Environment 89:137-148.

Malcolm, J. R., C. R. Liu, R. P. Neilson, L. Hansen, and L. Hannah. 2006. Global warming and extinctions of endemic species from biodiversity hotspots. Conservation Biology 20:538-548. 
Martin, D., and N. Tate. 1997. Surpop V2.0, introduction. Census Dissemination Unit, University of Manchester, Manchester, UK. Available online at: http://www.census.ac.uk/cdu/surpop.

McKinney, M. L. 2005. Urbanisation as a major cause of biotic homogenization. Biological Conservation 127:247-260.

Moody,A. 2000. Analysis of plant species diversity with respect to island characteristics on the Channel Islands, California. Journal of Biogeography 27:711-723.

Preston, F. W. 1960. Time and space and the variation of species. Ecology 41:611-627.

Pyšek, P. 1998. Alien and native species in central European urban flora: a quantitative comparison. Journal of Biogeography 25:155-163.

Ricklefs, R. E., and I. J. Lovette. 1999. The roles of island area per se and habitat diversity in the species-area relationships of four Lesser Antillean faunal groups. Journal of Animal Ecology 68:1142-1160.

Rodríguez, P., and H. T. Arita. 2004. Beta diversity and latitude in North American mammals: testing the hypothesis of covariation. Ecography 27:547-556.

Rosenzweig, M. L. 1995. Species diversity in space and time. Cambridge University Press, Cambridge, UK.

Santos, T., J. L. Telleria, M. Diaz, and R. Carbonell. 2006. Evaluating the benefits of CAP reforms: can afforestations restore bird diversity in Mediterranean Spain? Basic and Applied Ecology 7:483-495.

Seabloom, E. W., A. P. Dobson, and D. M. Stoms. 2002. Extinction rates under non-random patterns of habitat loss. Proceedings of the National Academy of Sciences, USA 99:11229-11234.

Šizling, A. L., and D. Storch. 2004. Power-law species-area relationships and self-similar species distributions within finite areas. Ecology Letters 7:60-68.

Storch, D., A. L. Šizling, and K. J. Gaston. 2003. Geometry of the species-area relationship in central
European birds: testing the mechanism. Journal of Animal Ecology 72:509-519.

Storch, D., K. L. Evans, and K. J. Gaston. 2005. The species-area-energy relationship. Ecology Letters 8:487-492.

Sugihara, G. 1981. $\mathrm{S}=\mathrm{CA}^{\mathrm{z}}, z$ congruent to $1 / 4-$ reply. American Naturalist 117:790-793.

Thomas, C. D., A. Cameron, R. E. Green, M. Bakkenes, L. J. Beaumont, Y. C. Collingham, B. F. N. Erasmus, M. F. de Siqueira, A. Grainger, L. Hannah, L. Hughes, B. Huntley, A. S. van Jaarsveld, G. F. Midgley, L. Miles, M. A. OrtegaHuerta, A. T. Peterson, O. L. Phillips, and S. E. Williams. 2004. Extinction risk from climate change. Nature 427:145-148.

Thrush, S. F., J. S. Gray, J. E. Hewitt, and K. I. Ugland. 2006. Predicting the effects of habitat homogenization on marine biodiversity. Ecological Applications 16:1636-1642.

Tjørve, E. 2003. Shapes and functions of speciesarea curves: a review of possible models. Journal of Biogeography 30:827-835.

Triantis, K. A., M. Mylonas, K. Lika, and K. Vardinoyannis. 2003. A model for the speciesarea-habitat relationship. Journal of Biogeography 30:19-27.

Turner, W. R., and E. Tjørve. 2005. Scaledependence in species-area relationships. Ecography 28:721-730.

van Gemerden, B. S., R. S. Etienne, H. Olff, P. W .F .M. Hommel, and F. van Langevelde. 2005. Reconciling methodologically different biodiversity assessments. Ecological Applications 15:1747-1760.

Veech J. A. 2000. Choice of species-area function affects identification of hotspots. Conservation Biology 14:140-147.

Watling, J. I., and M. A. Donnelly. 2006. Fragments as islands: a synthesis of faunal responses to habitat patchiness. Conservation Biology 20:1016-1025.

Werner, U., and J. Buszko. 2005. Detecting biodiversity hotspots using species-area and endemics-area relationships: the case of butterflies. 
Biodiversity and Conservation 14:1977-1988.

Williams, C. B. 1964. Patterns in the balance of nature and related problems in quantitative biology. Academic Press, New York, New York, USA.

Wissel, C., and B. Maier. 1992. A stochastic-model for the species-area relationship. Journal of Biogeography 19:355-362. 